\title{
Reactivity of Intrarenal Arteries to Vasoconstrictor and Vasorelaxant Polypeptides in Adult Stroke-Prone Spontaneously Hypertensive Rats
}

\author{
Yu-Jing GAO*, Yoshitaka Nishimura, Aritomo SuzukI and \\ Hideaki Higashino \\ Department of Pharmacology, Kinki University School of Medicine, Osaka- \\ Sayama, Osaka 589-8511, Japan
}

\begin{abstract}
The reactivity of intrarenal arteries to vasoconstrictor and vasodilator polypeptides was examined in adult stroke-prone spontaneously hypertensive rats (SHRSP). The contraction response to endothelin-1 (ET-1) was greater in SHRSP than in age-matched Wistar-Kyoto rats (WKY), and so was the $\mathrm{pD}_{2}$ estimate $(8.05 \pm 0.03$ in SHRSP, and $7.73 \pm 0.06$ in WKY ; $n=5, P<0.05)$. The contraction response to, and the $\mathrm{pD}_{2}$ estimate of, vasopressin were comparable in SHRSP and WKY. Neuropeptide Y did not contract the intrarenal arteries. In norepinephrine-precontracted arteries with intact endothelium, substance $\mathrm{P}$ and neurokinin A did not relax the arteries of either SHRSP or WKY, while calcitonin generelated peptide (CGRP) induced a profound relaxation response. Relaxation response to CGRP was significantly greater in SHRSP than in WKY. Atrial, brain, and C-type natriuretic peptides (ANP, BNP, CNP), vasoactive intestinal polypeptide (VIP), and peptide histidine isoleucine $(\mathrm{PHI})$ all caused relaxation responses, with a greater extent of relaxation to ANP, BNP, and VIP and a less extent to CNP and PHI. However, there were no significant differences in these relaxation responses between SHRSP and WKY. The current results revealed the character of heterogeneity of rat intrarenal arteries in response to vasoconstrictor and vasodilator peptides, and showed an enhanced reactivity to ET-1 and to CGRP in SHRSP.
\end{abstract}

Key words : calcitonin gene-related peptide (CGRP), endothelin, renal artery, SHRSP.

\section{Introduction}

Although spontaneously hypertensive rats (SHR) have been widely used in the study of essential hypertension for decades, the exact mechanisms underlying the development and maintenance of SHR high blood pressure have not yet been fully characterized. Renal cross

Correspondence to: Dr. Hideaki Higashino, Department of Pharmacology, Kinki University School of

Medicine, 377-2, Ohno-higashi, Osaka-Sayama, Osaka 589-8511, Japan.

Phone : 0723-66-0221 Ext. 3166, Fax : 0723-67-1820

e-mail : higasino@med.kindai.ac.jp

* Current address: Smooth Muscle Research Program and Department of Anaesthesia, McMaster University, Hamilton, Ontario, Canada. 
transplantation experiments have shown that genetically normotensive recipient rats develop hypertension after transplantation of kidneys from genetically hypertensive donor rats (even from donor rats at prehypertensive stage or those continuously treated with antihypertensive agents) (De Wardener, 1990 ; Rettig et al., 1990, 1993). Furthermore, a recent study has shown that genetically hypertensive recipient rats lowered their blood pressure after kidney transplantation from normotensive donors (Patschan et al., 1997). This increasing evidence suggests that the kidney abnormality is likely to be a causative factor for SHR hypertension.

It has been reported that renal vascular resistance in SHR is enhanced (Arendshorst and Beierwaltes, 1979). Since renal vascular beds play an important part in maintaining total peripheral resistance, and act as one of the main contributors to blood pressure formation, an increase of renal vascular resistance will directly contribute to blood pressure elevation. Increase of renal vascular resistance may also result in sodium retention by reducing renal blood flow, which may further accelerate hypertension genesis indirectly.

A body of evidence has suggested that some vasoactive polypeptides like calcitonin generelated peptide (CGRP), atrial natriuretic peptide (ANP), vasoactive intestinal polypeptide (VIP), may be involved in the hypertensive process of SHR or stroke-prone SHR (SHRSP) (Scott and Pang, 1983 ; Lee et al., 1988 ; Kawasaki et al., 1990). We previously found that the relaxant response to CGRP was significantly exaggerated in the intrarenal arteries (IRA) of SHRSP and SHR (Gao et al., 1994), indicating that the peptidergic regulation of IRA function is altered in these hypertensive rats. The reactivity of the IRA of these hypertensive rats to vasoconstrictor and to other vasorelaxant peptides, however, has not been addressed. In this study, therefore, to characterize other possible alteration(s) in reactivity to vasoactive peptides in the IRA of SHRSP we examined the response to vasoconstrictor peptides, and to vasodilator peptides in comparison with that to CGRP.

\section{Materials and Methods}

Animals

The study was performed on male SHRSP and WKY at the age of 24-28 weeks. The rats were bred and maintained at the Experimental Animal Center of Kinki University School of Medicine. The systolic blood pressure was $241.9 \pm 4.3(n=32)$ and $148.6 \pm 5.7(n=28) \mathrm{mmHg}$ for SHRSP and WKY, respectively (tail cuff method).

\section{Experimental Protocols}

The protocol was approved by Animal Care Committee of Kinki University School of Medicine. The methods have been described in detail in our previous paper (Gao et al., 1994). Briefly, the ring segments (approximately $1 \mathrm{~mm}$ long) of the third order branch of renal artery were horizontally mounted on two L-shaped tungsten wires (50 $\mu \mathrm{m}$ in diameter) with $200 \mathrm{mg}$ resting tension in a chamber $(2 \mathrm{ml})$ filled with Krebs-Henseleit solution. The solution was constantly bubbled with mixed gas of $95 \% \mathrm{O}_{2}$ and $5 \% \mathrm{CO}_{2}$ and maintained at $37^{\circ} \mathrm{C}$. Changes of tension were isometrically recorded. The viability of the artery preparation was tested with $\mathrm{KCl}(40 \mathrm{mM})$, and the integrity of endothelium was functionally assessed with acetylcholine 
$\left(10^{-6} \mathrm{M}\right)$ in a norepinephrine-precontracted state. The artery was abandoned if the relaxation to acetylcholine was less than $30 \%$ of papaverine-induced maximal relaxation. The concentration-response curve of vasoconstrictor peptides was assessed in quiescent state, and the response to vasorelaxant peptides was established in norepinephrine (NE, 6-8 $\left.\times 10^{-7} \mathrm{M}\right)$ precontracted rings. The precontraction to $\mathrm{NE}$ was stable and well maintained during the experiment.

\section{Chemicals}

All the peptides used in this experiment were the products of Peptide Institute Inc. Japan. Acetylcholine chloride was from Daiichi, Japan; Norepinephrine bitartrate was from Sigma, USA ; Papaverine hydrochloride was from Dainippon, Japan. All concentrations given were final concentrations in the bath chamber.

\section{Statistics}

The contraction response to peptides was normalized by the contraction to $40 \mathrm{mM} \mathrm{KCl}$. The magnitude of $40 \mathrm{mM} \mathrm{KCl-induced} \mathrm{contraction} \mathrm{was} \mathrm{comparable} \mathrm{in} \mathrm{SHRSP} \mathrm{and} \mathrm{WKY}$ (SHRSP : $176.3 \pm 28.4$, WKY : $172.5 \pm 32.8, n=6-8$, in $\mathrm{mg}$ ). The relaxation response to peptides was normalized by the maximal relaxation response generated by $10^{-4} \mathrm{M}$ papaverine. Results were expressed as mean \pm s.e.m. for $\mathrm{n}$ separate experiments. The $\mathrm{pD}_{2}$ estimate was determined by regression analysis as - log concentration that produced $50 \%$ of that agonist's maximal response observed. Significance was determined by Student's unpaired $t$-test. $P<$ 0.05 was considered as statistically significant.

\section{Results}

Contraction Response to endothelin-1 (ET-1), Arg ${ }^{8}$-vasopressin and neuropeptide $Y$

ET -1 produced a profound contraction response of the IRA in a concentration-related manner at the range of $3 \times 10^{-9}$ to $10^{-7} \mathrm{M}$. A greater percentage of contraction was observed in SHRSP when compared to that of WKY at all the concentrations except the lowest and the highest (Fig. 1A). The $\mathrm{pD}_{2}$ estimate of ET-1 was higher in SHRSP than in WKY $(8.05 \pm 0.02$ in SHRSP, $7.73 \pm 0.06$ in WKY; $\mathrm{n}=4-5, P<0.01$ ). Vasopressin also potently contracted the artery, but the magnitude of contraction to all of the concentrations and the $\mathrm{pD}_{2}$ estimates were comparable in SHRSP and in WKY ( $\mathrm{pD}_{2}$ estimates : $8.56 \pm 0.09$ in $\operatorname{SHRSP}(n=5)$, and $8.53 \pm 0.07$ in WKY $(n=6))$ (Fig. 1B). As shown in Fig. 1C, neuropeptide $Y$ caused neither any observable contraction, nor relaxation of the IRA at resting or precontracted state at all of the concentrations ranging from $10^{-8} \mathrm{M}$ to $10^{-6} \mathrm{M}$.

\section{Effects of Substance $P$ and Neurokinin A, in comparison with CGRP}

In NE-precontracted arteries, neither substance $\mathrm{P}$ nor neurokinin $\mathrm{A}$ produced any observable relaxation response in SHRSP and WKY (Fig. 2A and 2B). CGRP, at the range of $10^{-11}$ $\mathrm{M}$ to $10^{-7} \mathrm{M}$, elicited a dose-related relaxation response, and a greater magnitude of relaxation was found in SHRSP when compared to WKY at all concentrations except the lowest (Fig. 2C). 


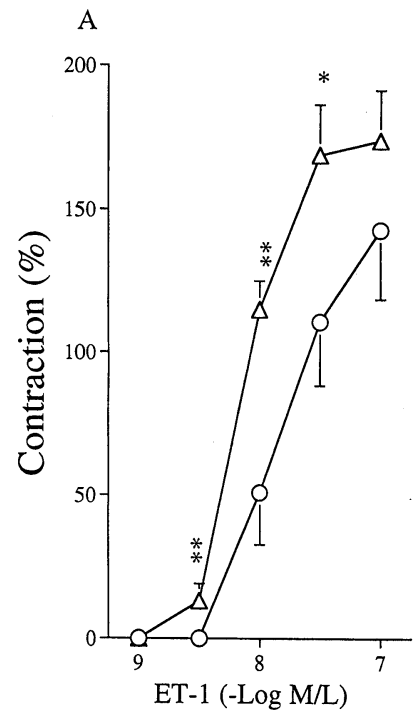

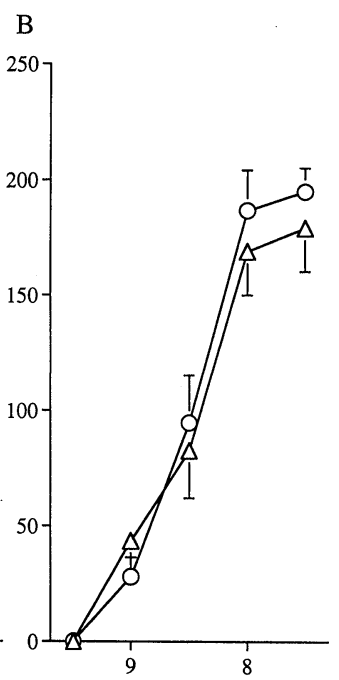

Vasopressin (- Log M/L)

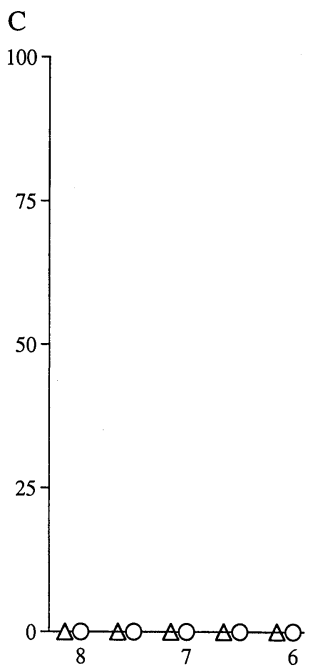

Neuropeptide Y (-Log M/L)

Fig. 1. Contractile effects of endothelin-1 (ET-1) (A), vasopressin (B), and neuropeptide Y (C) on the intrarenal arteries of $\operatorname{SHRSP}(\triangle)$ and WKY $(\bigcirc)$. The contraction was normalized by $40 \mathrm{mM} \mathrm{KCl}$-induced tension. ${ }^{*} P<0.05,{ }^{* *} P<0.01$ vs WKY $(n=5-6$, unpaired student's $t$ test).
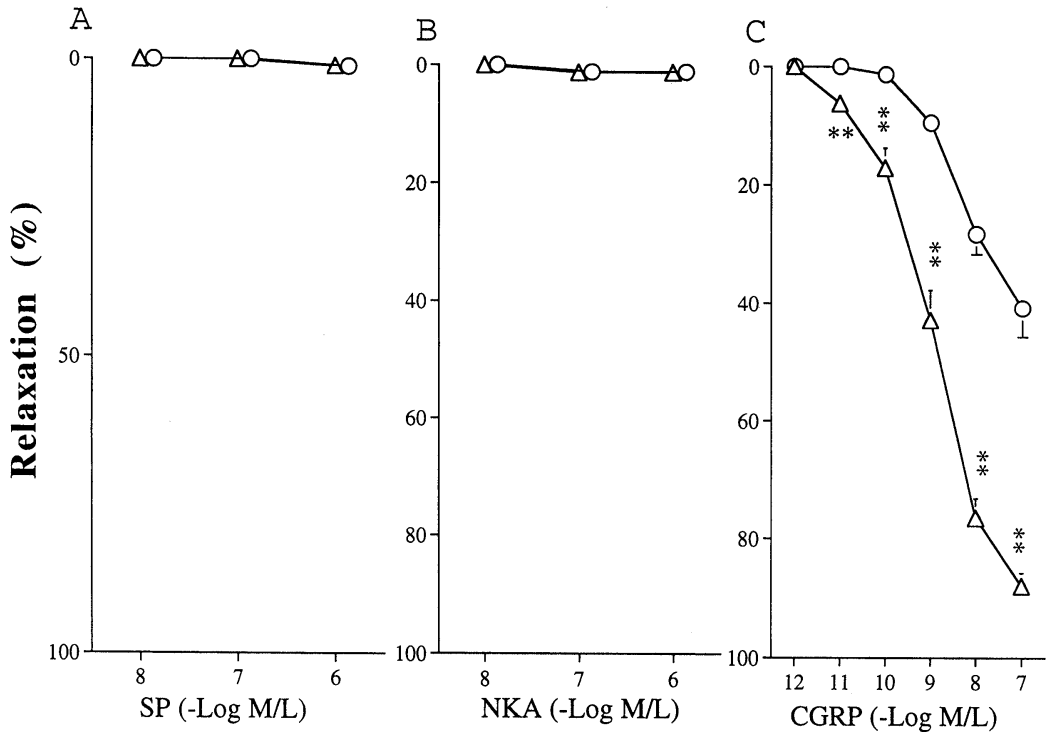

Fig. 2. Relaxant effects of substance P (SP) (A), neurokinin A (NKA) (B), and calcitonin generelated peptide (CGRP) (C) on the intrarenal arteries of SHRSP $(\triangle)$ and WKY $(\bigcirc)$. Arteries were pre-contracted with norepinephrine. Relaxation was expressed as \% of the maximal relaxation response to papaverine $\left(10^{-4} \mathrm{M}\right) . \quad{ }^{* *} P<0.01$ vs WKY $(n=5-6$, unpaired Student's $t$-test).

The $\mathrm{pD}_{2}$ estimate of CGRP was higher in SHRSP $(8.85 \pm 0.08, n=5)$ than in WKY $(8.13 \pm 0.07$, $n=6)(P<0.01)$. 


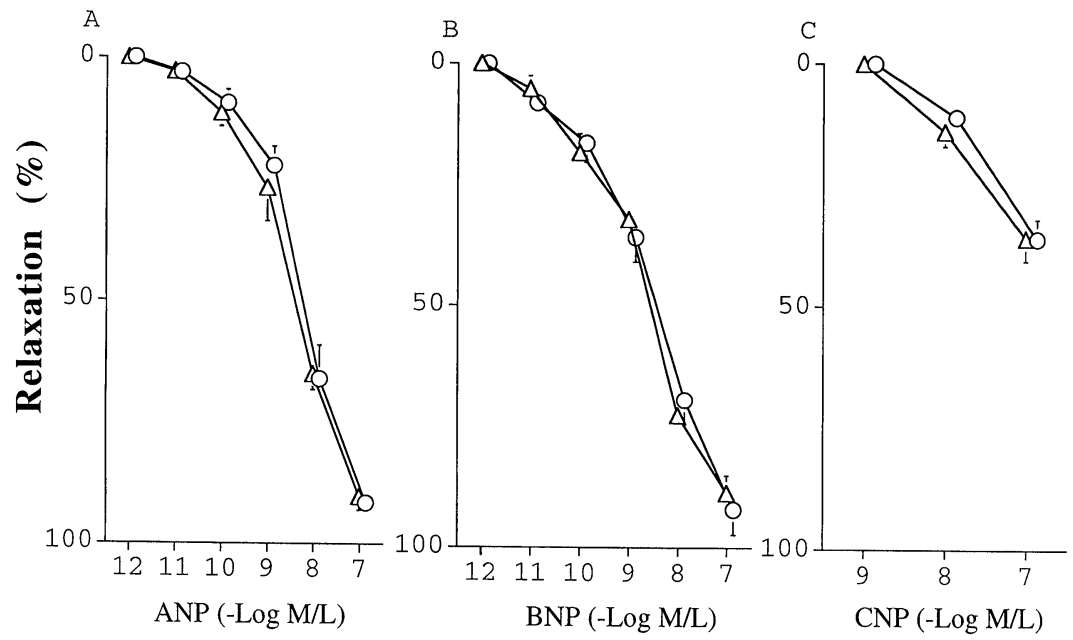

Fig. 3. Relaxant effects of atrial natriuretic peptide (ANP) (A), brain natriuretic peptide (BNP) $(B)$, and C-type natriuretic peptide $(\mathrm{CNP})(\mathrm{C})$ on the intrarenal arteries of $\operatorname{SHRSP}(\triangle)$ and WKY $(\bigcirc)$. Arteries were pre-contracted with norepinephrine. Relaxation was expressed as $\%$ of the maximal relaxation response to papaverine $\left(10^{-4} \mathrm{M}\right)$. ( $n=5-6$, unpaired Student's $t$-test).

\section{Relaxation Response to ANP, Brain and C-type Natriuretic Peptides (BNP and CNP)}

As illustrated in Fig. 3, ANP, BNP and CNP all induced a relaxation response of the IRA. The magnitudes of the maximal relaxation response to ANP and BNP were around 1.5 times greater than that to CNP. The $\mathrm{pD}_{2}$ estimates of ANP and BNP in SHRSP and WKY (ANP : $8.68 \pm 0.07$ and $8.63 \pm 0.16 ; \mathrm{BNP}: 8.87 \pm 0.13$ and $8.94 \pm 0.17$ ) were significantly higher than that of $\mathrm{CNP}(7.69 \pm 0.04$ and $7.6 \pm 0.06)(P<0.01, n=4-5)$. However, there were no significant
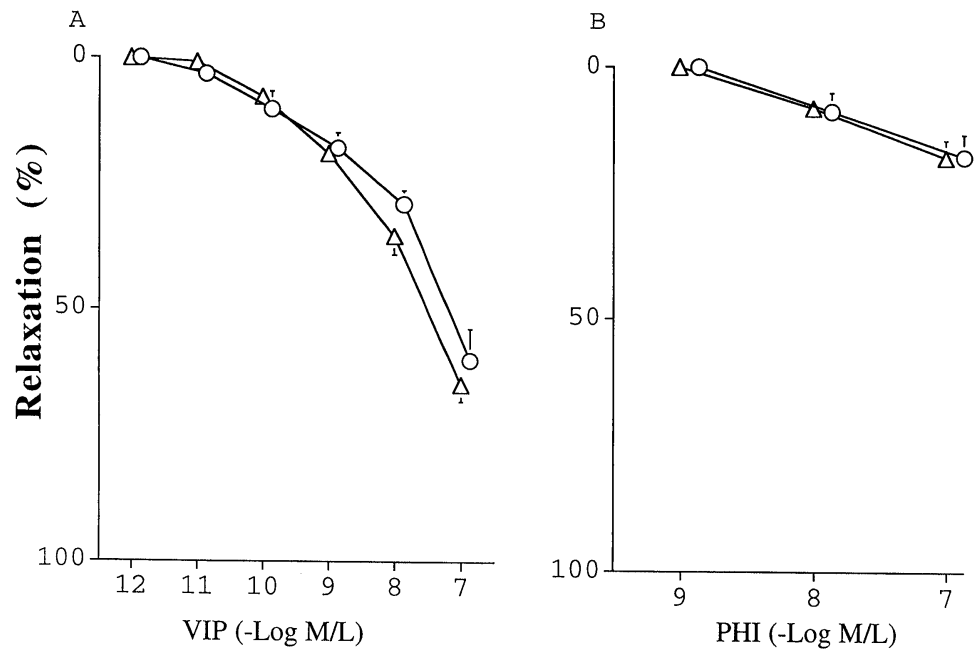

Fig. 4. Relaxant effects of vasoactive intestinal peptide (VIP) (A) and peptide histidine isoleucine $(\mathrm{PHI})(\mathrm{B})$ on the intrarenal arteries of $\operatorname{SHRSP}(\triangle)$ and WKY $(\bigcirc)$. Arteries were contracted with norepinephrine. Relaxation was expressed as \% of the maximal relaxation response to papaverine $\left(10^{-4} \mathrm{M}\right) . \quad(n=5-6$, unpaired Student's $t$-test $)$. 
differences in either the relaxation responses or the $\mathrm{pD}_{2}$ estimates of these peptides between SHRSP and WKY.

\section{Relaxant Response to VIP and Peptide Histidine Isoleucine (PHI)}

VIP $\left(10^{-11} \mathrm{M}\right.$ to $\left.10^{-7} \mathrm{M}\right)$ and PHI $\left(10^{-9} \mathrm{M}\right.$ to $\left.10^{-7} \mathrm{M}\right)$ generated a concentration-dependent relaxation response in the IRA of SHRSP and WKY. The magnitude of maximal relaxation response to VIP was about 3 times greater than that to $\mathrm{PHI}$, as shown in Fig. 4 . The $\mathrm{pD}_{2}$ estimates of VIP (SHRSP : $8.29 \pm 0.09$, WKY : $8.3 \pm 0.14$ ) were also greater than that of PHI (SHRSP : $7.71 \pm 0.06$, WKY : 7.68 \pm 0.1$)(P<0.05, n=5)$. However, there were no differences between SHRSP and WKY in reactivity to either VIP or PHI.

\section{Discussion}

In this study we examined the reactivity of IRA of SHRSP to vasoconstrictor and vasodilator peptides. Rat IRA exhibited heterogenous reactivity to vasoactive peptides: higher reactivity to constrictor peptides ET-1 and vasopressin and to vasorelaxant peptides CGRP, ANP, BNP and VIP; lower reactivity to vasorelaxant peptides CNP and PHI.

Substance $\mathrm{P}$, neurokinin $\mathrm{A}$, and neuropeptide $\mathrm{Y}$ did not cause observable responses. In the IRA of SHRSP, the reactivity to ET-1 and to CGRP was greatly enhanced.

Many studies have shown that endothelins are potent renal vasoconstrictors that enhance renovascular resistance (King et al., 1989; Loutzenhister et al., 1990 ; Fretschner et al., 1991). In the main trunk of the renal artery or on a perfused kidney of SHR, a higher sensitivity of the renal vasculature to endothelins has been reported (Tomobe et al., 1988 ; Miyauchi et al., 1989 ; Evangelista et al., 1992). In this study, we provided direct functional evidence showing the hypersensitivity of IRA to ET-1. Receptor autoradiography and molecular biological studies have revealed an overexpression of ET receptors in the intrarenal branches of the renal artery (Hocher et al., 1996) and an altered ratio of ET receptor subtypes in the cortex of SHR kidneys (Gellai et al., 1994). Furthermore, there has been a report showing that the content of immunoreactive ET-1 is much lower in the kidney of SHR than in WKY (Kitamura et al., 1989). Based on these observations, we postulate that the hypersensitivity to ET-1 shown in the IRA of SHRSP is likely to be the consequence of upregulation of ET receptors, and this upregulation may act to compensate for the lower concentration of ET in the SHRSP kidney. The pathophysiological significance of the increased reactivity to ET-1 in the IRA of SHRSP remains obscure. Two distinct subtypes of $\mathrm{ET}$ receptors, $\mathrm{ET}_{\mathrm{A}}$ and $\mathrm{ET}_{\mathrm{B}}$, have been cloned in mammals (Bax and Saxena, 1994). The current results can not distinguish which subtype is responsible for the enhanced response shown in SHRSP, and further study is needed.

Vasopressin is a strong vessel pressor peptide in renal circulation. It exerts its vasoconstrictor action via specific membrane receptors (Lariviére et al., 1989). There is controversy of the effects of vasopressin in SHR: some reports show exaggerated reactivity to vasopressin in perfused SHR or SHRSP kidneys (Berecek et al., 1980; Feng and Arendshorst, 1996), while some others do not (Fink and Brody, 1979; Collis et al., 1980). Our study with isolated IRA of SHRSP showed that the reactivity to vasopressin did not alter in comparison with normoten- 
sive WKY, suggesting the renal artery, at least the intrarenal segment we used, did not have hyperactivity to vasopressin. Neuropeptide Y, which itself is a potent vasoconstrictor in rats (Zukowska-Grojec et al., 1987 ; Andriantsitohaina and Stoclet, 1988; McAuley and Westfall, 1992), is usually co-localized with norepinephrine in perivascular sympathetic nerves (Ekblad et al., 1984). A number of reports have shown hyperactivity of peripheral sympathetic nerves including the renal nerve in SHR (Okamoto et al., 1967 ; Coote and Sato, 1977; Thoren, 1987). However, the IRA of SHRSP and WKY did not react to exogenously applied neuropeptide Y. Our results indicate that neuropeptide $\mathrm{Y}$ is not an effective regulator of IRA function.

As we have demonstrated previously (Gao et al., 1994), the IRA of SHRSP exhibited higher reactivity to CGRP, and we hypothesized this hyperactivity to CGRP to be the consequence of upregulation of CGRP receptors due to dysfunction of CGRP-containing perivascular nerves. An increase of reactivity to CGRP may compensate, at least partially, for the decreased function of CGRP-containing prevascular nerve and may help to decrease high blood pressure by improving vasodilation, if there is sufficient CGRP available. In this study, we examined the reactivity to substance $\mathrm{P}$ and to neurokinin $\mathrm{A}$, the two most abundant peptides which may co-localize with CGRP in sensory nerve fibers (Holzer, 1988). However, neither substance P nor neurokinin A produced any observable response up to the concentration of $10^{-6} \mathrm{M}$, a 10 fold higher concentration than that of CGRP at which the maximal relaxation response was induced. Our functional results suggested that rat IRA lacked receptors of these tachykinins and were in agreement with previous immunohistochemical findings (Mulderry et al., 1985).

Two subtypes of natriuretic peptide receptor (NPR-A and NPR-B) have been proposed (Kollen et al., 1991). The NPR-A receptor is relatively more sensitive to ANP and BNP, while NPR-B receptor is relatively more responsive to CNP (Suga et al., 1992). Receptor autography study also revealed that ANP and BNP shared binding sites in rat kidney (Oehlenschlager et al., 1989). Among the natriuretic peptide family, ANP and BNP potently dilated rat IRA, whereas CNP displayed a much weaker action. This implies that the main subtype of natriuretic peptide receptor in rat IRA is NPR-A. The reactivity of IRA of SHRSP to these natriuretic peptide family members did not differ from that of WKY, suggesting their role in regulating IRA function is not altered. In contrast, the report by Wei et al. (1994) showed an increased relaxation response to ANP and a reduced relaxation response to CNP in the aorta of SHR. The differences between our results and theirs may be due to the difference in arteries employed, the IRA vs aorta, or to the difference in rats used, SHRSP vs SHR.

In the mesenteric arteries of SHRSP, an increased density of VIP-containing innervation has been reported (Lee et al., 1988). We found, in this experiment, that VIP induced a moderate relaxation response, and that PHI, a homologous peptide of VIP (Lündberg et al., 1984), caused a slight relaxation response in the IRA, but there were no significant differences between SHRSP and WKY. These results indicated that the reactivity to VIP and to PHI were not changed in the IRA of SHRSP.

Throughout this study, we found that rat IRA was highly sensitive to ET-1, vasopressin, CGRP, ANP, BNP and VIP, less sensitive to CNP and PHI, and did not react to neuropeptide $\mathrm{Y}$, substance $\mathrm{P}$ and neurokinin $\mathrm{A}$. These differences in reactivity suggest different roles of these peptides in modulating the IRA function. In SHRSP, ET-1 induced contraction and 
CGRP-induced relaxation were significantly increased, indicating these two peptides are possibly involved in the pathophysiological process of hypertension.

\section{References}

Andriantsitohaina, R. and Stoclet, J.C. (1988). Potentiation by neuropeptide Y of vasoconstriction in rat resistance arteries. Br. J. Pharmacol. 95: 419-428.

Arendshorst, W.J. and Beierwaltes, W.H. (1979). Renal and nephron hemodynamics in spontaneously hypertensive rats. Am. J. Physiol. 236 : F246-F251.

Bax W.A. and Saxena P.R. (1994). The current endothelin receptor classification : time for reconsideration? Trends Pharmacol. Sci. 15: 379-386.

Berecek, K.H., Schwertschlag, U. and Gross, F. (1980). Alteration in renal vascular resistance and reactivity in spontaneously hypertensive rats. Am. J. Physiol. 238: H287-H293.

Collis, M.G., Demay, C. and Vanhoutte, P.M. (1980). Renal vascular reactivity in the young spontaneously hypertensive rats. Hypertension 2 : 45-52.

Coote, J.H. and Sato, Y. (1977). Reflex regulation of sympathetic nerve activity in the spontaneously hypertensive rat. Cir. Res. 40 : 571-577.

De Wardener, H.E. (1990). The primary role of the kidney and salt intake in the aetiology of essential hypertension. Clin. Sci. 79: 193-200.

Ekblad E., Edvinsson, L., Wahlestedt, C., Uddman, R., Hakanson, R. and Sundler, F. (1984). Neuropeptide Y co-exists and co-operates with noradrenaline in perivascular nerve fibers. Regul. Peptides 8: 225-235.

Evangelista S., Maggi C.A. and Castellucci, A. (1992). Effects of endothelin (ET)-1, ET-3 and ET$(16-21)$ on the isolated and perfused rat kidney from normotensive and spontaneously hypertensive rats. Jpn. J. Pharmacol. 59 : 239-241.

Feng, J.J. and Arendshorst, W.J. (1996). Enhanced renal vasoconstriction induced by vasopressin in SHR by $\mathrm{V}_{1}$ receptors. Am. J. Physiol. 271: F304-F313.

Fink, G.D. and Brody, M.J. (1979). Renal vascular resistance and reactivity in the spontaneously hypertensive rats. Am. J. Physiol. 271: F128-F132.

Fretschner, M., Endlich, K., Hayashi, K. and Horton, C. (1991). Direct visualization of effects of endothelin on the renal microcirculation of the split hydronephrotic rat kidney. Renal Physiol. Biochem. 14: 112-127.

Gao, Y.J., Nishimura, Y., Suzuki, A. and Yoshida, K. (1994). Relaxant effects of calcitonin generelated peptide on isolated small renal arteries in stroke-prone spontaneously hypertensive rats. J. Smooth Muscle Res. 30: 9-19.

Gellai, M., DeWolf, R., Pullen, M. and Nambi, P. (1994). Distribution and functional role of renal ET receptor subtypes in normotensive and hypertensive rats. Kidney International 46:12951301.

Hocher, B., Rohmeiss, P., Zart, R., Diekmann, F., Vogt, V., Metz, D., Fakhury, M., Gretz, N., Bauer, C., Koppenhagen, K., Neumayer, H.H. and Distler, A. (1996). Function and expression of endothelin receptor subtypes in the kidney of spontaneously hypertensive rats. Cardiovasc. Res. 31 : 499-510.

Holzer, P. (1988). Local effector functions of capsaicin-sensitive sensory nerve endings: involvement of tachykinins, calcitonin gene-related peptide and other neuropeptides. Neuroscience 24: 739-768.

Kawasaki, H., Saito, A. and Takasaki, K. (1990). Changes in calcitonin gene-related peptide (CGRP)-containing nerve activity in hypertension. Brain Res. 518: 303-307.

King, A.J., Brenner, B.M. and Anderson, S. (1989). Endothelin : a potent renal and systemic vasocon- 
strictor peptide. Am. J. Physiol. 256: F1051-1058.

Kitamura, K., Tanaka, T., Kato, J., Ogawa, T., Eto, T. and Tanaka, K. (1989). Immunoreactive endothelin in rat kidney inner medulla: marked decrease in spontaneously hypertensive rats. Biochem. Biophys. Res. Commun. 162: 38-44.

Kollen, K.J., Lowe, D.G., Bunnett, G.L., Minamono, N., Kangawa, K., Matsuo, H. and Goeddel, D.V. (1991). Selective action of the B-natriuretic peptide receptor by C-type natriuretic peptide (CNP). Science 252: 120-123.

Larivière, R., Baribeau, J., St-Louis, J., Schiffrin E.L. (1989). Vasopressin receptors and inositol triphosphate production in blood vessels of SHR. Can. J. Physiol. Pharmacol. 67 : 232-239.

Lee, RMKW., Nagahama, M., McKenzie, R. and Danniel, E.E. (1988). Peptide-containing nerves around blood vessels of stroke-prone spontaneously hypertensive rats. Hypertension 11 (Suppl. I) : 117-120.

Loutzenhister, R., Epstein, M., Hayashi, K. and Horton, C. (1990). Direct visualization of effects of endothelin on the renal microvasculature. Am. J. Physiol. 258: F61-F68.

Lündberg, J.M., Farenkrug, J., Hokfelt, T., Martling, C.R., Larsson, O., Tatemoto, K. and Anggard, A. (1984). Co-existence of peptide HI (PHI) and VIP in nerves regulating blood flow and bronchial smooth muscle tone in various mammals including man. Peptide 5 : 593-606.

McAuley, M.A. and Westfall, T.C. (1992). Possible location and function of contractile effects of neuropeptide Y receptor subtypes in rat mesenteric arterial bed. J. Pharmacol. Exp. Ther. 261 : 863-868.

Miyauchi, T., Ishikawa, T., Tomobe, Y., Yanagisawa, M., Kimura, S., Sugishita, Y., Ito, I., Goto, K. and Masaki, T. (1989). Characteristics of pressor response to endothelin in spontaneously hypertensive and Wistar-Kyoto rats. Hypertension 14: 427-434.

Mulderry, P.K., Ghatei, M.A., Rodrigo, J., Allen, J.M., Rosenfeld, M.G., Polak, J.M. and Bloom, S.R. (1985). Calcitonin gene-related peptide in cardiovascular tissues of rat. Neuroscience 14 : 947-954.

Oehlenschlager, W.F., Baron, D.A., Schomer, H. and Currie, M.G. (1989). Atrial and brain natriuretic peptides share binding sites in the kidney and heart. Eur. J. Pharmacol. 161: 159-164.

Okamoto, K., Nosaka, S., Yamori, Y., Matsumoto, M. (1967). Participation of neural factors in the pathogenesis of hypertension in the spontaneously hypertensive rat. Jpn. Heart J. 8: 168180.

Patschan, O., Kuttler, B., Heemann, U., Uber, A. and Rettig, R. (1997). Kidneys from normotensive donors lower blood pressure in young transplanted spontaneously hypertensive rats. Am. J. Physiol. 273: R175-R180.

Rettig, R., Folberth, C., Stauss, H., Hopf, D., Waldherr, R. and Unger, T. (1990). Role of kidney in primary hypertension: a renal transplantation study in rats. Am. J. Physiol. 258: F606F611.

Rettig, R., Schmitt, B., Pelzl, B. and Speck, T. (1993). The kidney and primary hypertension: contributions from renal transplantation studies in animals and humans. J. Hypertens. 11: 883-891.

Scott, T.M. and Pang SC-N. (1983). Changes in jejunal arteries in spontaneously hypertensive and normotensive rats following neonatal treatment with capsaicin. Acta Stereol. 2: 127-133.

Suga, S., Nakao, K. and Hosoda, K. (1992). Receptor selectivity of natriuretic peptide family, atrial natriuretic peptide, brain natriuretic peptide, and C-type natriuretic peptide. Endocrinology 130 : 229-239.

Thoren, P. (1987). Efferent renal nerve traffic in the spontaneously hypertensive rats. Clin. Exp. Hypertens. [A] : 9(Suppl. 1) : 259-279.

Tomobe, Y., Miyauchi, T., Saito, A., Yanagisawa, M., Kimura, S., Goto, K. and Masaki, T. (1988). Effects of endothelin on the renal artery from spontaneously hypertensive and Wistar Kyoto 
rats. Eur. J. Pharmacol. 152: 373-374.

Wei, C.M., Kim, C.H., Khraibi, A.A., Miller, V.M. and Burnett, J.C., Jr. (1994). Atrial natriuretic peptide and $\mathrm{C}$-type natriuretic pepetide in spontaneously hypertensive rats and their vasorelaxing actions in vitro. Hypertension 23(2) : 903-907.

Zukowska-Grojec, Z., Marks, E.S. and Haass, M. (1987). Neuropeptide Y is a potent vasoconstrictor and a cardiodepressant in rat. Am. J. Physiol. 253: H1234-H1239.

(Received August 14, 1999 : Accepted October 1, 1999) 